\title{
LEXICAL CREATIVITY IN THAI ENGLISH FICTION
}

\author{
Pairote Bennui \\ pairote1977@hotmail.com \\ University of Malaya
}

Azirah Hashim

azirahh@um.edu.my

University of Malaya

\begin{abstract}
Unlike some varieties of English in Southeast Asia, the notion that there is a 'Thai English' is debatable. This paper examines distinctive non-native features of a lexicon found in contemporary Thai writing in English to ascertain if English in this Expanding Circle country is developing its own linguistic norms. An analysis of features of lexical creativity in five short stories and novels is carried out to determine whether the characteristics found indicate that a Thai English vocabulary exists. An 'integrated framework' which combines concepts in World Englishes by Braj B, Kachru, Peter Strevens, and Edgar W. Schneider is adopted in this study. It appears that certain categories of lexical creativity in the fiction examined represent five indicators of Thai English - contextualization, innovation, nativization, transcultural creativity, and localization - and reveals a developing non-native variety of English.
\end{abstract}

\section{Keywords}

lexical creativity, Thai English, fiction

\section{About the Author}

Azirah Hashim is a Professor at the English Language Department, Faculty of Languages and Linguistics, and Dean of the Humanities and Ethics Research Cluster, University of Malaya, Malaysia.

Pairote Bennui is currently a PhD candidate in the field of Varieties of English, Faculty of Languages and Linguistics, University of Malaya, Malaysia. Since 2005, he has been an English lecturer at Western Languages Program, Faculty of Humanities and Social Sciences, Thaksin University, Songkhla, Thailand. 


\section{Introduction}

English in Thailand has not been widely accepted as another non-native variety given the absence of particular features of nativization, autonomy, and creativity in its developing norms of English. Therefore, the concept of 'Thai English' has been controversial because a native variety of English has been recognized as the norm in various domains in Thailand. American English has played a major role in the country as it is linked to modern technology, mass media, and popular culture, but British English is also significant since this variety implies a political resemblance between Thailand and Britain. A number of Thais tend to prefer this variety because of Britain's constitutional monarchy system (Kirkpatrick 17). Hence, Thai people have developed their way of speaking English by modeling these two varieties whereas other native varieties - Canadian, Australian, and New Zealand Englishes - have not been as popular although their influence has been undeniable. Moreover, American and British English norms for spelling, vocabulary, and grammar have been used in the leading Thai English newspapers, namely Bangkok Post and The Nation respectively. These papers have been written and edited by more native English speakers than overseas-educated Thais, thus they provide a limited range of Thai English discourse. Corollarily, reading British/ American English literature has acquired social value among educated Thais since it allows them access to Anglo culture and modernity. As a result, Thai literature in English has become marginalized since it embodies indigenousness rather than internationalization. Consequently, the local or Thai inflection of English has not been fully accepted among Thais themselves and, as such, English has been viewed as an international language, a medium between Thais and foreigners, rather than an intra-national one. Thais, however, seldom converse and write in English locally which can explain the absence of localized forms of English. For more than a century, English has been a legacy of high-ranking family members and elites while its more commonplace association as a compulsory school subject contributes only marginally to the education and national consciousness of the general population. Whereas the former can speak and write near-native English given their access to opportunities to study abroad, most Thais are poor in English since English in local schools is taught in Thai.

Over a period of time, English in Thailand has progressively developed beyond an educational function as English and Thai have gained more channels of linguistic contact. Nonetheless, Thai English has not been referred to as a new and distinct hybrid because the use of English in Thailand does not have the following features that make an English a variety (Butler "A View" 82 ): (i) standard and recognizable patterns of pronunciation passed on from different generations; (ii) certain words and phrases expressing the prominent physical and social circumstances and considered peculiarity to the variety; (iii) history - a sense that this English variety occurs because it is a part of the history of the language community; (iv) 
a literature created without apology in that variety of English; and (v) reference works like dictionaries and style guides that show the people in such community have decided on spoken and written norms for their English. In the context of the present study, these issues address: (i) 'whether there are standard patterns of pronunciation in Thai English'; (ii) 'whether there are unique words and phrases for a Thai variety of English';(iii) 'whether there is a historical development of Thai English'; (iv) 'whether there is a creative literature written with the use of Thai English as linguistic expression'; and (v) 'whether a dictionary of Thai English and a manual of Thai English styles are available as a significant model for Thai users of English.' This paper addresses the second and fourth concerns above. Like English literature in the Outer Circle, Thai literature in English, a part of contact literature, represents localized forms of linguistic, literary, and cultural creativity in English which are different from native English literature. Hence, this paper engages those two questions by exploring the lexicons created by Thai literary writers of English for their pragmatic and rhetorical effects on the local and international readers which contribute to the shaping of a Thai variety of English.

As a species of non-native English writing, Thai English literature is recognized as a product of linguistic deficiency or deviation in which linguistic forms violate Standard English. However, Rajeswary Pandharipande claims that deviations present in creative writing and newspaper registers coined by non-native English writers and journalists are "intentionally meaningful deviation" which reveals linguistic creativity, not 'errors' (155). Informed by this argument, this paper examines the concept of linguistic creativity used by Thai English authors to develop the formal elements of characterization and theme which diverge from those in Anglo English literature.

The present study analyzes and describes features of lexical creativity in English fiction by Thai writers in order to ascertain if the features used indicate a Thai variety of English. Although the genre is considered prestigious, writing fiction entails a prose style in which language formations on everyday speech patterns of Thais are constructed. Moreover, writing fiction requires creating a lexicon, a basic but vital unit of linguistics, which enters the larger sets of phrases, clauses, and sentences for literary discourse. As such, this paper aims to explore lexicosemantic and lexico-morphological variation of Thai English words from Standard English, mirroring 'non-native innovation' in a number of Thai English novels and short stories.

\section{Studies in Lexis of Thai English and Asian Englishes}

Research on Thai English lexicons has been rather limited. In her study, Susan Butler indicates the presence of such in the Macquarie Dictionary Project of Asian English lexical corpus. Butler identifies a number of Thai English words frequently used by Thais and foreigners: "minor wife, hill tribe, farang, sanuk, wai, 
klong, long-tailed boat, sticky rice, tuk-tuk, longans, and rai" ("World English" 352354, "A View" 192-193, and "The Needs" 91-92). This corpus allows English users in other regions to understand Asian Englishes. In a similar project, Parinda Jantori investigates the lexical innovation in Thai English from 30 feature articles of the English newspaper "Bangkok Post" from June 30 - August 11, 2006. Informed by the Kachruvian framework on Bilinguals' Creativity and Contact Literature (1986), her analysis reveals that lexical innovation lies in four processes of linguistic distinctiveness. The first refers to the transfer of religious, socio-cultural elements which are present in the word 'Phra' (monk in English), the addressing term about kinship (e.g., Loong Ho or Uncle Ho), occupation (e.g., Khru Kittisuk Yoosuk), and the social status title (e.g. Khunying Dr. Mallika Wannakrairot). The second pertains to translation as seen in the words 'axe-pillow' and 'long-tail boat'. The third refers to hybrid constructions of Thai and English words (e.g., tuk-tuk drivers) and an English and Thai compound (e.g., a floating raan ahaani). Finally, lexical borrowing contains independent words (e.g., rai, farang, and mae nam) and lexical borrowing with reduplication - ubosot (ordination hall) and kwan (spirits of life). These lexical items constitute "Thainess" in a Thai English newspaper. Likewise, Kingsley Bolton notes many Thai English words from the Macquarie Dictionary database compiled in the Grolier International Dictionary. Examples of typical words are shown as follows: 'ajarn' (teacher); 'benjarong' (a decorative Thai jar with five colors); 'farang'; 'fighting fish'; 'hill tribe'; 'kha' and 'khrap' (addressed by a female and male, respectively, to show politeness and respect as well as agreement with someone or understanding what has been said); 'khun' (a polite title used before the first name of a man or woman (e.g., Khun Ananda); 'khunying' (a title of honour awarded to a Thai woman); 'klong' (canal); 'krengjai' (consideration); 'long-tail boat'; 'merit-making'; 'minor wife'; 'nong' (a younger brother or sister or a form of address used by an older person to a younger person as a sign of friendliness or politeness); and 'phi' (an older brother or sister or a polite form of address from a younger to an older person, to show respect). These words suggest that a Thai variety of English is developing ("English"). In the same vein, Philip Mathias notes that English words have been adapted to a Thai context in three popular online forums, namely Thai Visa Forum, Ajarn Forum, and ThailandQA.com between January 2007 and January 2010. Such words which are interpreted according to John Macalister's four types of lexical integration and adaptation (2007) are of loanwords, loan translations, semantic loans, hybridization, and coinages. Obviously, lexical borrowing can be considered the most common lexical innovation used in the three forum discussions as it consists of 32 items. Among these, certain words are found in the studies by Butler, Jantori, and Bolton, that is, "ajarn, farang, katoey, khlong, sanuk, tuktuk, and wai" (11). Moreover, loan translations, coinages, and hybrid items are the subsequent strategies of lexical innovation used in the forum as they carry 9, 6, and 3 items respectively. In this regard, the use of the words "merit making, minor wife, and sticky rice" (11) under 'loan translations' are parallel to those found 
by Butler and Bolton. Overall, these studies reveal that English lexicons in Thai socio-cultural contexts seem to be more important for Thai and foreign speakers of international English through different texts, suggesting the possibility that Thai English exists.

Understanding other studies in Asian Englishes lexis is also fruitful to this study as they provide points of divergence and convergence. One study written by Michael Meyler presents Sri Lankan English (SLE) words after compiling a dictionary of SLE. Such words are the outcome of the use of English by Sri Lankan speakers whose vernaculars are Singhalese, Tamil, and Malay. Furthermore, Meyler notes that other languages influencing SLE words are Hindi, Arabic, Dutch, and Portuguese. The most common lexis from Hindi is 'lakh' (one hundred thousand). In Indian English, this word is directly applied as 'six lakh rupees' while SLE users express 'six lakhs of rupees' (57). Other outstanding items are collocations for the words 'coconut', 'rice' and 'tea' (e.g., coconut arrack, coconut husk, coconut oil, rice belly, rice flour, rice packet, tea dust, teas estate, and tea plucker) (58). These words have been standardized for a Sri Lankan variety of English. Similar to SLE, Malaysian English (MalE) is a variety which is influenced not only by Malay and Tamil but also by Chinese linguistic elements. Rita Abdul Rahman Ramakrishna analyses lexical borrowing in 184 MalE short stories published from 1957 to 2006 using the framework adapted from Graeme Kennedy's loanwords in New Zealand English (2001) and Kari Dako's lexical borrowing in Ghanaian English (2002). Her study suggests that MalE writers have created two types of vocabulary according to a Malaysian variety of English. In the first, morphologically marked borrowed words are divided into five categories with prominent examples - derivation (e.g., gedeberish and ex-reformasi), inflection (e.g., lepaking, towkay's, and pujas), multiple affixation (e.g., un-gedeber-like), noun modifier (e.g., kondai bus and balik kampung trip), and compounding (e.g, kway teow man and sari-clad) (9-12). For another type, culturally-based borrowed words carry three categories. Firstly, content words appear in 16 domains - food, place, arts, flora and fauna, weapon, health, festival, transportation, people, clothing and accessories, religion, superstitious beliefs, games, marriage, numeral and measures, and miscellaneous. The most common loan belongs to food (e.g., satay, dim sum, muruku, and ais kacang). Secondly, addressing terms consist of amma, Poh Poh, and Ayah, etc. Lastly, titles are seen in Dato'/Dato, Datuk, Tan Sri, and Kapitan Cina (12-17). These morphological and semantic components of loanwords reflect the richness and complexity of lexical creativity embedded in MalE literature. Like MalE, Hong Kong English (HKE) is shaped by Chinese influence. Besides, this variety partially concerns Indian English. This is examined by Patrick Cummings for lexical innovation in HKE from a variety of texts that circulate in Hong Kong (e.g. newspapers, web pages, food packaging, everyday speech, books, academic papers, memoirs, and government publications, etc). In this respect, Kachru's Concentric Circle of English (1985) is used as an approach for the analysis because the concept of lexical innovation 
of English here seems to herald the nativization of English. Features of lexical innovation in HKE are based on indigenous languages interfacing English. Firstly, Chinese Pidgin English consists of the following: (i) the word 'chop' (e.g. chop boat and chow chow chop); (ii) the word 'hong' (e.g., the Co-hong and the hong boat); (iii) Malay words (e.g., penang lawyer, go down, and catty); and (iv) Portuguese words (e.g., joss house, baby amah, and comprador) (36-41). Secondly, Indian English in HKE appears in a food domain (e.g., saffron, sago, and tiffin) and a business domain (e.g., shroff and coolie) (43-44). Thirdly, Cantonese in HKE embodies loanwords (e.g., Kit Fat or first wife and Heung Cheung or village leader), hybrid items (e.g., gaylo and hoisin sauce) (46-47). Finally, common core derived lexical innovation or 'semantic shifts' is made up of three domains. Politically, the word 'astronaut' in HKE means "a person who works in one place and whose family home is far away in another place" (50). Socially, the word 'banana' means "a Chinese person who has become westernized and is only Chinese or 'yellow' on the outside and is Caucasian or 'white' on the inside" (54). In business, 'a short-time hotel' refers to 'a hotel that rents rooms by the hour' (56). All these words exhibit the Hong Kong variety of English. These three studies are indicative of an Asian Englishes vocabulary in the Outer Circle. Meanwhile, the following two studies are reflected in the Expanding Circle. Firstly, Jian Yang presents a data-based analysis of 59 lexical borrowing items found in 84 articles in the leading two China English newspaper, namely China Daily and Beijing Weekend, between May and October 2004, informed by the frameworks used in Liwei Gao's lexical acculturation of English the Chinese context (2001), Susan Romaine's Bilingualism (1995) and Einar Haugen's analysis of linguistic borrowing (1950). It was found that China English journalists cited loanwords and loan translations from Chinese languages. Loanwords appear as the followings: (i) culture-specific lexical items (e.g. 'Hua Mulan' or a legendary heroine, 'Baozi' or a steamed filled bun, and 'nianhua' or Spring Festival paintings); (ii) nonce borrowings or the occurrence of loans in typographic markings that include italics, boldface, and quotation marks, and in meta-linguistic commentary or a translation of a term; and (iii) necessary borrowings found in the Chinese BLI Corpus and the Brown Corpus (428-430). Furthermore, loan translations look more foreign than they appear due to the underlying meaning of Chinese culture (e.g., beauty ceremony, economic crime, and foreign experts) (1, 430-431). These two facets of lexical borrowing make evident that Chinese English is a new non-native variety. Finally, Stephen Moore and Suksri Bounchan, in their study, reveal the perspectives of 144 fourth-year students as well as 10 lecturers of English-Major Programs at Royal University of Phnom Penh on the notion of 'Cambodian English' (CamE). The former subjects' views were elicited via a questionnaire while the opinions of the latter subjects were processed during a group discussion. The study yielded data related to perceptions concerning teaching and learning preference and using English in Cambodia. Moreover, the study revealed the presence of CamE and its linguistic patterns. It appears that $47.1 \%$ of the students acknowledge 
this variety whereas $52.9 \%$ did not. Meanwhile, the teachers in the group discussion affirmed the presence of CamE by describing its phonological, grammatical, and morphological features. In this regard, CamE words are of four types - clipping (e.g., 'cher' for teacher), loanwords (e.g., motodop, prahok, and sangkat), semantic shifts of English words in French sense (e.g., 'promotion' for 'generation'), and coinages (e.g. 'baby duck egg' for 'embryonic duck') (118-120). Being parallel to China English, Cambodian English carries a decent number of lexical borrowings. These two studies indicate a manifestation of lexical creativity in the Expanding Circle English.

Similar to the related studies cited, our analysis of a Thai English lexicon samples Asian Englishes dictionaries as well as journalistic and online texts, which manifests in five categories - loanwords, hybridization, loan translation, modes of addressing and referencing, and coinages. Meanwhile, the remaining studies in Asian Englishes conform to the notion of varieties rather than those in Thai English as they are conducted via not only dictionaries, newspapers, and websites, but also academic and governmental papers, spoken discourse, group discussions, and literary texts. Hence, there are other two categories of lexical innovation - semantic shifts and clipping. Moreover, the interface between English and other Asian vernaculars is more apparent. In terms of approaches, the Kachruvian framework is popular in studies on both Thai English and Hong Kong English; however, other models in linguistic borrowings by different scholars are also cited. Overall, all the studies indicate that the items of lexical innovation reveal the existence of Asian varieties of English; nevertheless, they also reveal two aspects of the research gap. One is that research in lexical borrowing has been more emphasized than that in other categories, so there will be many others which can be regarded as innovations. Another is that some approaches used are not of World Englishes. As a result, the present study attempts to bridge the gap by exploring more classifications of lexical creativity with the sophisticated models of World Englishes and a systematic process of textual analysis as well as utilizing literary texts which are found in only Malaysian English here in order to find out whether a number of English and Thai lexicons in Thai English fiction are parallel to the concepts of lexical creativity and a Thai variety of English as mentioned in those previous studies.

\section{Conceptual Framework}

The conceptual framework of this study is based on a combination of concepts in World Englishes by Braj B. Kachru, Peter Strevens, and Edgar W. Schneider. Five concepts by the three scholars that are characteristic of non-native Englishes lexicons are used in the analysis in this study. A description of and theoretical argumentations regarding such concepts are provided below.

Contextualization is a concept adapted from 'the Firthian framework of linguistic science' (1957) by Kachru to study 'Indianization of English' from creative literature. 
Textually, this notion concerns the context of a situation in which language is an integral part of culture. Indeed, transfer involves context due to the transference of speakers/writers' native language and culture (L1 and $\mathrm{C}_{1}$ ) into L2 forms (English). Kachru found four processes of lexico-grammatical transfer representing Indian English lexicon - lexical transfer, translation, shifts, and calques (Indianization 99-127).

As this concept is based on Kachru's study on Indian English literature, a number of critical observations attend the phenomenon of Indian English. Indeed, this concept does not provide an explicit dichotomy between mistakes and innovations. There are no indicators to ascertain what type of influence from the Indian context can be attributed to mistakes and what influence results in a productive deviation. Moreover, neither Kachru nor an Indian English writer Meenakshi Mukherjee, whose novel was examined in relation to this concept, has substantially accounted for the Indianization of English, so a clearer account of 'contextualization' of Indian English with 'a naturalism approach' is necessary. Contextualization, here, is a method of associating linguistic items of mistakes and deviations with Indian cultural items. Successfully describing the process of contextualization requires scholars to link the founding linguistic items of Indian English to the linguistic and cultural context. Moreover, whether an example Kachru gives - 'flower bed' - is a mistake or a deviation is uncertain. Kachru labels this item as register confusion and recommends that it is avoidable. This shows that Kachru fails to apply the mistake-deviation distinction in developing this study. Besides, some examples are insufficiently discussed in the way of contextualization; for instance, the item 'the forbidden meat' carries no information about what kinds of meat an Indian reader may assume. This means Kachru's contextualization does not represent a solid sociolinguistic analysis as details of linguistic terms for special audiences are inadequate. All these problems reveal that Kachru's contextualization becomes more an anecdote of item-by-item than a grounded and systematic analysis (Dasgupta 125-129). This comment is radical; the paradigm 'contextualization' is underdeveloped. Indeed, this paradigm is not an original but an adaptation. Such comments are probably valid as this paradigm is the earliest linguistic analysis of new English literature. Kachru later theorizes the notions of 'mistakes, deviation, and innovation' under the three concentric circles (1985) and bilinguals' creativity and contact literature $(1986,1987)$ in order to affirm the varieties of English in World literature.

Innovation is based on an integration of Kachru's classification of hybridization as a prominent lexical innovation in South Asian Englishes (Indianization 152162) and Kachru's innovation typology that "the productive linguistic processes used for such innovations are shared with other varieties, though the lexical realization in each variety may be different" (e.g., modes of reference and address and collocations) ("Standards" 20-21). 
This concept was a subject in the debate on the Concentric Circles Model of English between Lord Randolph Quirk and Braj B. Kachru in the 1985 issue of the journal English Today. Quirk strongly disagrees with this model for several reasons. In this regard, he considers the term 'linguistic innovation' as 'deficit linguistics' or 'errors' which are inferior to Standard English. Kachru responded to Quirk by providing 'six fallacies' about uses and users of English to support this model. In light of 'innovation', Quick's criticism ignores the functional appropriateness of languages in sociolinguistic contexts distinctly different from the Inner Circle. This means the deviations or errors by ESL users should be viewed an appropriate use of linguistic distinctiveness for communicative purposes rather than errors (Jenkins 63). Hence, the mentioned classification and typology of innovation have been theorized. On the other hand, Ayo Bamgbose advocates this concept by proposing five internal factors of innovation - demographic, geographic, authoritative, codification, and acceptability factors - in order to prove the statement "an innovation is seen as an acceptable variant while an error is simply a mistake or uneducated usage. If innovations are seen as errors, a non-native variety can never receive any recognition" (2). Demographically, innovations depend on the number of English users with three ability levels - acrolect, mesolect, and basilect. Innovation is commonly expressed in mesolectal and basilectal varieties while it is rarely found in the acrolect. If it is used by the larger amount of the users of the highest variety, the innovation will be more accepted. Geographically, an innovation requires its spread across different sociolinguistic and geographical background of English throughout the world. For example, Indian English can be divided into sub-varieties like Hindi English, Urdu English, and Marathi English. Once innovation has the greater spread over various regional varieties, it will be more recognized. In terms of codification, innovations become evident in the written form in grammar books, lexical or pronunciation dictionaries, course books, and manual. When the use of innovation is standardized through solid sources or texts, this means innovative forms are acceptable. Authoritatively, innovations are actually used by writers, teachers, media practitioners, examination bodies, publishers, and influential opinion leaders. If unconventional forms of English by those users are codified, innovations will be recognized. In light of acceptability, innovations are admitted to the ultimate test. Once innovative forms are accepted by more influential writers or reputable authorities, they stand a greater chance of becoming assimilated to correct forms. As a result, codification and acceptability are the most important parameters of innovations (3-5).

Nativization is adopted from Kachru's study on bilinguals' creativity and contact literature and Schneider's study on structural nativization. The former describes the main features of linguistic and literary creativity of a bilingual writer through three aspects of nativization: nativization of context, nativization of cohesion and cohesiveness, and nativization of rhetorical strategies. Only the second one directly concerns lexical creativity. It involves "collocation extension, the use and 
frequency of grammatical forms, lexical shift, hybridization, and loan translation" (Kachru, Alchemy 165-168). In the latter approach, phonological, grammatical, and lexical processes are the most significant parameter of the Dynamic Model of the evolution of Postcolonial English (PE). For this study PE words are lexical expansion via four processes: lexical borrowing from indigenous languages commonly found in terms for places, animals, and plants, etc; hybrid compounding; coinages; and semantic shifts (Schneider 78-82). These processes result in nativization of English words in divergence from native norms.

Indeed, nativization remains tenable. Bolton (Chinese Englishes) affirms the success of this framework, the result of the three circles. This paradigm dislodged the Anglo-centric literary canon from its dominant status in order to privilege new literatures or contact literature in English by African, Asian, and Caribbean bilingual writers who have undergone nativization. This linguistic paradigm is valuable for reincarnating English in non-Anglo literatures and cultures. Indeed, this framework informs the theme 'Bilingual's creativity' of World Englishes that is extended to linguistics, literature and pedagogy. The first two areas are included in this present framework. Likewise, Rodney H. Jones contends that the study of Bilinguals' creativity should focus on discourse analysis, especially regarding the stylistic production of texts in which linguistic adjustments are made for psychological, sociological, and attitudinal reasons. Jones also validates the manner in which Kachru designs Bilinguals' creativity to meet contact literature with a sociolinguistic approach which is different from other stylistic approaches (470). This paradigm centers on the interface between the two terms 'contact literature' and 'contact language'. However, some scholars disagree with the significance of such terms. William O'Grady and John Archibald (620) (qtd. in Joseph 132) propose that 'contact language' conveys inevitable linguistic change through an interaction between speakers of a language and those of another language. However, 'contact literature' does not immediately lead to a parallel system of literary change because 'creativity' and 'aesthetic' as they operate in the literary imagination probably act as 'alien' elements that cause simplified language in the literary process, resulting in linguistic impurity. Moreover, writers are perhaps burdened by convention, society, and ideology of literatures in other languages. Besides, literature partially removes the nature of contact language. In this view, this framework does not imply its unfruitfulness but it assumes some risk factors that do not make for a convergence between language contact and literature contact.

Transcultural creativity is grounded by the process of 'translation', 'transfer', and 'transcreation' in the literary creativity of World Englishes. This notion contains three types of intercultural crossover considered as the powerful stylistic tools that are adopted from Larry E. Smith's (1992) study - intelligibility, comprehensibility, and interpretability. Only the first two types are utilized due to their lexical relevance. The first emerges in a speech fellowship in which members of different socio-cultural and linguistic backgrounds share the underlying 
linguistic resources with mutual intelligibility. Denotative meanings of words are decoded and presented without problems understood by the members. The second occurs in speech communities in which members share identical literary, cultural, and religious canons. Certain lexis in the native culture of 'religious and ritualistic discourse', translated and transcreated in English (e.g., Sanskritization and Persianization), requires 'connotative meaning' for comprehension (Kachru, “Transcultural” 271-275).

This concept has not been commented on by any scholars but it was examined by Edmund Bamiro ("Transcultural"), who modifies the definition of 'transcultural creativity' alongside 'translation equivalence', 'transcreation', and 'translingualism. Indeed, the first two are grounded in this paradigm while the last, defined by Patrick Scott (75), is "the purposive and artful reproduction within one language of features from another language" (2). Bamiro merely adapts this concept by Kachru to his own lexico-semantic category of 'translation equivalents' (1991) in order to analyze the bilinguals' transcultural creativity in Nigerian English literatures. That is, he does not fully utilize three types of intercultural crossover - intelligibility, comprehensibility, and interpretability - for this analysis. However, all aspects of the findings are likely to parallel those mentioned in two types although Bamiro does not directly convey - modes of address (type 1), prayers-invectives-ritual communication (type 2), and idiomatic expressions (type 2). In short, only the partial conception of this paradigm.

Localization is adapted from Strevens's localized forms of English (LFEs). Localization is an emerging linguistic feature of English expressions by non-native users in which local cultural patterns are embedded and different from those of a native speaker. Two defining parameters of a LFE are relevant to lexical creativity: lectal and varietal range as well as existence of standard and non-standard forms. First, lectal range defines each LFE as having its own characteristic range between "acrolect, mesolect, and basilect" and its own social interpretations of when each LFE is appropriate and what role in society is assumed by a speaker. Varietal range in a given LFE includes the following elements: (a) registers of English regarding subject matters in lexical forms, etc; (b) formality-familiarity of situation affecting word choices; and (c) the appropriateness of slang, colloquialism, swearing, and abuse in different groups of people. Second, existence of 'standard' and 'nonstandard forms' of dialect in an English-using community in relation to lexis is that English faces only trivial variation of grammar and lexis, not accent. Overall, examples of LFEs are non-native English literatures given the presence of English diversity and a LFE source (65-76).

Robert Keith Johnson does not accept LFEs of intra-type. He states that no 'intranational' variety of English, L1 or L2, is appropriate for international purposes but only or LFEs of inter-type exists as the definable and teachable purposes to international students, so such an intra-type is suitable to a narrow range of purposes. Moreover, that intranational varieties are used by populations while English for 
international purposes is used by individuals makes his concept of international English unreal (1-2). Likewise, this form remains unacceptable despite attempts to standardize it. Clifford Prator argues that an LFE is inferior to the native English form since it is not an effect of a process of high efficiency of teaching-learning and it is not accepted as a pedagogical norm that leads to a loss of intelligibility. These scholars do not accept all functions of LFEs as they are seen as an infringement of the purity of English. LFEs are justified as they have defining and differentiating parameters as well as types and emerging features of English around the world. Such parameters seem to be useful for a framework for analyzing linguistic, literary, pedagogical, and professional features of LFEs in both ESL and EFL societies.

In total, the five concepts are mainly framed as postcolonial English linguistic and literary theories. Although three of them by Kachru and Strevens were formed three decades ago, they are still considered contemporary paradigms since they have been debated and modified by a number of recent scholars but they are rarely examined for studies in Thai English. Meanwhile, two other concepts by Kachru and Schneider were proposed in the late twenty and early twentieth century, respectively, but they have been applied to few studies in the Expanding Circle English. As a result, all five concepts are chosen as the so-called eclectic framework due to their manifestation of lexical creativity in New Englishes.

\section{Methodology}

The data for this study comprises three collections of short stories as follows:

(1) Dragon's Fin Soup: Eight Modern Siamese Fables (DFS) (2002), by Sucharitkul P. Somtow, provides local themes about someone caught in between Thai and western cultures. The author has been nominated for and has won many awards. This book was the best short story nominee for the World Fantasy Award in 1996;

(2) Sightseeing (STS) (2005), by Rattawut Lapchareonsap, involves the clash between locality of Thai life and modernity of Westernization. The author has won the Avery Jules Hopwood Award and the Andrea Beauchamp Prize; and

(3) The Umbrella and Other Stories (UOS) (1998), by Supasiri Supunpaysaj, carries themes on ghosts, family life, childhood and beliefs in karma. The most distinguished story 'The Umbrella' was awarded the second prize in the UNESCOPEN in 1993.

In addition, two novels are chosen as follows:

(1) Shadowed Country (SDC) (2004), by Pira Canning Sudham, is a compilation of two sequel books, "Monsoon Country" and "The Force of Karma". This novel depicts the suppressed life of north-eastern Thais in the 1960's and 1970's under despotic regimes, and a driving force under poverty and injustice in Thailand. The first book was a nominee for the Nobel Prize in 1990; and

(2) Chalida (CLD) (2002), by Salisa Pinkayan, narrates a high-society Thai family drama in the context of Thailand's political problems in 1969 through a woman's 
perspective. The writer is a well-known columnist of feature articles for a Thai English newspaper The Nation.

These writings are selected mainly because of the reputation of the authors. They represent Thai English literature because their themes involve the Thai way of life. Moreover, the language used shows the writers' creative ability and approximation of native English writers. Nevertheless, their written expressions appear in a range of linguistic variation from native English literature. Although the writers are overseas-educated Thais, their Thai identity is palpable as seen in the settings, characters, and points of view regarding indigenization. The readers of such fiction are usually educated Thais and foreigners.

With regard to method of analysis, this study employs 'textual analysis' that requires three processes as follows: (i) Text selection: certain lexical items infringing semantic and morphological rules of Standard English vocabulary but regarding 'lexical creativity' from each page of the five books are marked out; (ii) Text coding and categorizing: each lexical item in an excerpt is coded with the abbreviated book title, story or chapter title, and the page number; moreover, a collection of the items are classified into different categories of lexical creativity developed by the researcher via studying related studies as well as approaches; and (iii) Text analysis and interpretation: the lexical features from the categories found are interpreted using related studies and the selected approaches for identifying indicators for a Thai variety of English.

\section{Lexical Creativity in Thai English Fiction}

The selected fiction presents ten types of lexical creativity as given below. Each is discussed alongside related studies on lexical innovation in contact literature and in Thai English.

\section{Lexical Borrowing}

Lexical borrowing is used when "there is no known English equivalent of a word or phrase" (Cesarano 30). Although such equivalent is found, non-English words are still used as they serve more emotional and cultural meanings in the non-Anglo context than certain English lexis. They are divided into two types below.

(a) Independent lexical borrowing refers to loanwords for which meanings are not translated; borrowed items of Thai language autonomously occur in English sentences, mainly for Buddhist terms - "wat, samadhi, sangha, Chedi, gutti, prapiksu, and saisin."

Another function of loan words that stands out refers to food. Consider the following excerpt from CLD: 
Ex.1

They accosted everyone with their fried bananas, hot noodles, green mangos, purple mangosteens, grilled pork, sticky rice and somtam (Pinkayan 32-33; ch. 2).

The word 'somtam' is not given its English equivalent, 'green papaya salad', as it is a popular Thai food among local and foreigners. Other words representing Thai foods are gaeng masman, luk chin, kao tom, and pad thai respectively.

Other functions of independent lexical borrowing appear in the clothes items: "phathung, panung, and sarong." Furthermore, the domain of human characteristics which refers to ethnicity, gender, and occupation consists of various words: farang, siew, huana, mohfarang, and sopheni. Moreover, the parts of Thai house and its components also consist of such words (e.g., bannkhunluang, sala, moobaan, soi, and klong). The musical instrument domain comprises three words: kaen, pinai, and taphon. Additionally, other functions encompass a few words as follows: (i) money (baht); (ii) greetings (wai); (iii) sports (chok muay); (iv) countries and cities (patetfalang and muang); (v) transportations (tuk-tuk); (vi) feelings (sanuke); and (vii) taboo (huakuai).

(b) Reduplicating lexical borrowing concerns loans with repetition in their meaning translated in either brackets or appositives or modified in contextual clues. Similar to independent loans, this type carries the highest amount of terms in Buddhism and superstition: krod, Vipasana, ngaan wat, Yama, khao song, winyan, jaothi, saan-phraphum, kwan, piprapor, luke-pi, and phii krasue. Likewise, the food items that include desserts, rice, dishes, and vegetables are: awsuan, tongyip, tongyod, kanom chan, gaeng kiow wan, baimaakood, takai, kao jaow, kao niaw, and pladaek.

Clearly, the domain of human traits also provides many salient Thai English words. An instance from SDC is displayed.

Ex. 2

The transvestite or kratoey promised Bruce a blissful time (Sudham 263; bk. 1, ch.14).

The word 'kratoey' is repeated after the word 'transvestite'. It could be another popular Thai English word which appears in various texts. Other words under this domain are chaolay, luk krueng, mianoi, mialuang, and naama.

Many other words appear in different domains. The house items are "baan, banvimarnman, and baansongsiam." Examples of Thai animals are palaa, lukegop, jung, and maa. Three words that belong to the plant items are "phuttachat, yaplong, and ton yang." Moreover, words for greetings are sawatdee and khobkhun. 
In addition, the following domains contain a few items: (i) cities (Kroong-thep and changwat); (ii) clothes (sabai); (iii) taboo (Dawson); and (iv) marriage (sinsod).

Both independent and reduplicating loans share some functional features. The majority of them come from Thai, which includes Pali-Sanskrit, while some are from Chinese and a few are Malay. These constitute the main languages in Thailand.

The loanwords found are compared to those in the earlier studies in Thai English and other Asian Englishes. Some items - "farang, sanuke, wai, klong, tuk-tuk, and kwan" - can be considered unique Thai English words as they are replicated in research by Butler ("World English" 352-354, "A View" 192-193, and "The Needs" 91-92) as well as in studies by Jantori, Bolton ("English"), and Mathias (11). Further, certain words "katoey, luk krueng, mia noi, sin sod, soi, somtam, and wat" are also duplicated in Mathias's study (11). Similarly, three words of this study parallel those found in a Thai English novel Until the Karma Ends: A Plot to Destroy Burma by Pongpol Adireksan. The word 'chock muay' is an informal version of the word 'Muay Thai' (a Thai kick-boxing style). Moreover, the words 'pathung' and 'panung' are the synonyms of the word 'pasin' as they refer to lady's clothes (Watkhaolarm 154). In this respect, the word 'sarong', a Malay loan in Thai language found in this study, is used for men's clothes. This distinctive Asian English lexis for both sexes appears in different terms in Malaysian English: 'batik sarong,' sarong' or 'sarung' (Tan 8). The word 'pad thai' not only appears in Mathias's work (11) but can also be grouped under the Chinese-Hokkien word 'kuay teaw' (noodle) in a Singapore English novel The Adventures of Holden Heng (1986) by Robert Yeo (Wong 114) as some Thais call 'kuay teaw pad thai'. In addition, the word 'saisin' is similar to the Tamil Malaysian English word 'thali' in K.S. Maniam's fiction (Lowenberg 253) due to its use for a sacred device for a religious ritual. Additionally, the words 'moobaan' and 'Baan' are synonymous to a Malaysian English word 'kampung' in Karim Raslan's short stories (Govendan 117). Similarly, the Thai word 'tonyang' and the Philippine English one 'hinagdong' in Children of the Ash-Covered Loam and Other Stories by N.V.M Gonzalez (Platt et al. 180-181) refer to different kinds of trees, but they are loans of a specific tree in certain cultures. Likewise, the words "tongyip, tongyod, and kanomchan" are similar to the Indian English words "samosas, nan, and jalebis" in Salman Rushdie's Midnight's Children, Shame, and The Satanic Verses (Langeland 16-17) because of traditional Thai desserts.

\section{Modes of Address and Reference}

Specific words for communication with and reference to a social member regarding his/her ranking and status appear in 'titles and kinship terms'. The selected fiction presents five modes of addressing and referencing used by the Thai characters as follows: 
(a) Modes of Addressing and Referencing for the Royal Family Members: Only two words for monarchical registers are found - "The Divine King Chulalongkorn" and "His Divine Majesty Rama the Sixth." Consider the following extract from DFS:

Ex.3

I didn't want a ride from my father because I had a secret errand or two to do on the way to the cemetery where Khun Chuad Snit's remains had lain since the time of the Divine King Chulalongkorn (Somtow 40; "Lottery Night").

The word 'divine' displays 'atheisms' via the King of Thailand. Buddhism is atheist, so the King becomes 'godly' or 'holy' when being referred to by a commoner character who uses the pronoun 'I' to refer to himself.

(b) Modes of Addressing and Referencing for Monks and Learned Men: Titles for this group of Thai characters are - Pra, Naak, and the Pundit Piksu. An example from SDC is given below.

Ex. 4

Pra Sungwian Suwanapumi, the monk, carefully paced the path; his eyes observed only [...] (Sudham 101; bk.1, ch.5).

Monks are hierarchically superior to many others and are significant Buddhist figures in Thai society. The word 'Pra' is a formal title added to particular given names of monks. Meanwhile, the title 'Naak' displays a temporary title for a monkto-be. It will be changed to 'Pra' once he is ordained. After the ordination, a monkto-be who has become 'pra' will be called 'Pundit Piksu', which is the title for a newly graduated monk.

(c) Modes of Addressing and Referencing for Kinship Terms: Thailand is a collective and hierarchical society, so respectful titles and kinship terms which are hierarchically ordered are shown - Taanpor (Gracious father), Taanmae (Gracious mother), Taanluke (Gracious son/daughter), khun chuad (a greatgrand mother or father), khun yaa (a father's mother), khun por (a father), khun mae (a mother), and khun pii (an elder brother/sister).

(d) Modes of Addressing and Referencing for Commoners: Lexical choices used for addressing and referencing Thai commoners vary according to class, gender, career, and style. The royal title 'khunying' (lady) is distinctive for commoners. Next, the titles "kru, krooyai, and ajarn" are honorific for teacher positions. Then, the titles 'khamnan' and 'puyaibaan' represent leaders in a local administration. 
Moreover, the terms - Taan (sir), Nay (master), Ta (senior villager), Nong (unreal younger sister), Phuan (friend), $A i$ and $E$ (endearment terms between male and female and for pets) - are hierarchically referred.

(e) Modes of Addressing and Referencing for Chinese Thais: Thailand contains a large amount of Chinese ethnics, so referencing terms for these characters are unusually depicted - sia (an affluent businessman), thaokae (a shop owner), jek (Chinese people), apae (Chinese old man), and muoi (Chinese girl). Indeed, the words 'sia' and 'thaokae' have also been used for non-Chinese Thais who fit this expression of wealth.

A number of emerging addressing and referencing terms in Thai English resemble those in Jantori's, Bolton's ("English"), and Mathias's works - phra, khun, khunying, kru, ajarn, nong, and phi. Similarly, the titles 'pra' in Thai and 'sandara' in an Indian English novel A Train to Pakistan (Mehrotra 428-429) are referred to the honorific terms for Buddhist and Sikh leaders respectively. Similar to the Arabic and Turkish terms in an Egyptian English novel The Map of Love (1999) by Ahdaf Soueif, the Thai terms 'puyaibaan' and 'khamnan' are equivalent to the term 'Umdah' since they refer to 'village chief'. Moreover, the terms 'the venerable abbot' and 'luangpoh' are parallel to 'Fadilatukum' due to titles for high ranking religious important persons. Furthermore, the Thai item 'khun pii' is similar to 'Abeih' because of the titles for oldest brothers (Albakry and Hancok 226). Apart from these, the Thai title 'taan' is equal to the title 'tuan' in the Malaysian English literature And the Rain my Drink (Yap 68) because both refer to 'sir'. Besides, the title 'khunying' which is found in Jantori's research also parallels the Malaysian English title 'Datuk' from Karim Raslan's A New Year's Day Lunch in Kia Peng (Azirah Hashim 37; Rita Abdul Rahman Ramkrishna 17). Although the former is restricted to only females while the latter can be awarded to both genders, the titles provide recognition to the bearers. A similar term in Thai English and Malaysian English is 'thaokae' (Tan 463) as this Chinese word is borrowed in Thai. In addition, the Thai referencing term for commoners like 'phuan' can be compared to the terms 'Comrade Young Shao' and 'Brother Shao' in China English in a novella In the Pond by Ha Jin (Zhang 308) although it is not a translated item. Finally, the Thai kinship term 'khun por' shares a feature with the forms 'the father of the children' in Sri Lankan English fiction by Punyakate Wijenaike (Dissanayake and Nichter 114-115) and 'Ayah' in Malaysian English short stories (Rita Abdul Rahman Ramakrishna 16).

\section{Loan Translation}

Three kinds of loan translation are found: word-for-word translation, fixed collocation and swear words. 
(a) Word-for-word translation: This refers to English lexis directly translated from Thai. All translated loans lie in the rank-shifted type, not the rank-bound one. Rank-bound translations involve English words in which non-native writers attempt to translate at the same rank in their $\mathrm{L}_{1}$ lexis constituting parts. Meanwhile, rank-shifted translations do not have morphological structure of English words in the equivalent rank of L1 words (Kachru, Indianization 133134). Consider the following excerpt from DFS:

Ex. 5

Her hair was like a woman [...] I remembered that she had once been the third minor wife of a provincial functionary of the government of His Divine Majesty Rama the Sixth (Somtow 50; "Lottery Night").

The word 'minor wife' is rank-bound translated. It would be rank-shifted if it had been translated as 'wife minor' /mia no:j/.

Interestingly, some of the words share semantic features of Asian Englishes water-taxi, water-bus, shop house, vote selling, Four-Faced Brahmin shire, and lottery-dreamer. Meanwhile, many words mirror the unique Thai context - sticky rice, canal taxi, elephant-trekking business, the annual district draft lottery, heartstopped building, rent-free land, coconut room, red-ants' nest, little car toilet, dogeating ethnic group, rice winner, kite-flying wind, and short-time hotel users. In addition, the words 'Multi-Great-Uncle' and 'multi-uncle' are similarly translated with regard to the old generation of Thai kinship as no English words can serve this meaning.

(b) Fixed collocation: Collocation refers to the way words have relations and combinations together. Fixed collocations allow no or a few words to collocate as they are mostly idiomatic expressions of a particular culture (e.g., trenchant criticism and fired with enthusiasm) (Hill 48, 50). In World Englishes, the loan translation creates collocations that are "unfamiliar to Inner Circle users of English" as they convey innovative lexicon with a strong socio-cultural reference to non-native Englishes (Kachru and Smith 107). Hence, this study contains many collocations with Thai idiomatic words and their English translations. Majority of the items are rank-shifted translations as shown in the following instance from DFS:

Ex. 6

The interview with the spirit doctor was set for the following week (Somtow 178; "Fiddling for Water Buffaloes").

The word 'spirit doctor' refers to a Thai shaman who subdues souls or ghosts. The word 'spirit' can be combined with a only a limited number of words. For examples, 
'guardian spirit', 'spirit house, 'the supernatural and spirits of dark things', and 'the Spirits of the Universe' emerge in this study. Meanwhile, some items irrelevant to 'nature' like 'car' (spirit car) and 'pen' (spirit pen) are not usually found in Thai collocations.

Meanwhile, a few words are rank-bound translated into English. An example from UOS is provided.

Ex. 7

But, none, none, I tell you, is as without a Gift-From-Heaven as you are

[...] I fear that Heaven may have forgotten you (Supunpaysaj 47; "Sister Ondine").

The word 'Gift-From-Heaven' is hyphenated and ordered in Thai. It is a Thai collocation as Thais believe that all gifted people are provided by gods in the heaven. Similarly, the word 'heaven' can be collocated with some items in Thai such as the verb 'go to heaven' (die/orgasm), so it cannot be combined with some like 'swim' (swim to heaven). Other rank-bound words are - two-headed (song-hua), the Goddess Moon (Pra Chan), and sub-human beings (set-manud).

Other collocations of Buddhist beliefs, ceremonies, and practices are: reborn, afterlife, soul-destroying, past karma, the 227 tenets, soul-beckoning mantra, the rain-begging rite, temple-arrested, next world, the Ruler of the Earth and the Sky, soul-binding rite, and sacred circle. Moreover, words which are feminine in the Thai culture are Mother Earth and the Goddess of Rain. Furthermore, words of habitual features of Thais are sour-faced, heavy-hearted, ant-like army, and longback louse. Finally, a political collocation is the Might of Corrupt.

(c) Swear words: Curse that is translated from English into Thai, namely 'animal' or 'sat', seems to be only used as a harsh word.

The words "minor wife, hill tribe, and sticky rice" represent the prominent loan translation in this study because they are replicated by those in Butler's ("World English", "A View”, and “The Needs"), Bolton's ("English”), and Mathias's works. In this respect, the word 'minor wife' is synonymous to the term 'subordinate mistresses' in the Thai English autobiography My Boyhood in Siam (Watkhaolarm 149). The Thai English collocation "the supernatural and spirits of dark things" and 'Heart-stop building' are similar to the Tamil Malaysian English word 'fearhaunted nights' in K.S. Maniam's The Third Child (1981) (Velautham 101). Likewise, collocations for Buddhism and Hinduism in Thai English - "soul-beckoning mantra, sacred circle, and soul-binding rite" - are very much related to the Sri Lankan English word 'religious amulet' in James Goonewardene's Dream Time River (1984) (Fernando 125). Furthermore, the words 'coconut room' and 'rice winner' in Thai English and 'coconut husk' and 'rice packet' in Sri Lankan English (Meyler 58) are interrelated because of the use of natural items for linguistic construction. Apart 
from these, the words 'short time hotel users' in Thai English and 'a short-time hotel' in Hong Kong English (Cummings 56) are semantically convergent. Besides, the word 'animal' in Thai English seems to be the general basis for cursing as found in the China English term like 'son of a turtle' in a novella In the Pond (Zhang 308 ); and the Indian English term "cock-eyed son of a bowlegged scorpion" in Mulk Raj Anand's Untouchable (Lowry 228).

\section{Coinages}

Coinage is "the process of inventing a new word" because users "cannot establish any connection with any existing word." It is evident in "the names of people and places, or of trademarks for products" (Low and Brown 71). According to Bamgbose (106-107), coinages also involve the "coining of new lexicon from local languages or from pidgin either directly or in translation, e.g. barb from barber" in Nigerian English (qtd. in Bamiro "Nigerian Englishes" 12). Coinages in this study arise for two different purposes as given below.

(a) English trademarks or advertising of products in Thailand: the authors tend to use words 'AT\&T', 'Coke', and 'Coca-Cola' that are authentic in the Thai society. On the contrary, they recreate the following coinage from SDC by adapting to a branded Thai product:

Ex. 8

They must make use of a space on the pavement to set up a food stall for one of their ant-like army of minions to sell the so-called Five Diamond Roast Chicken (Sudham 499; bk. 2, ch. 20). (Underline added)

The underlined phrase is coined from 'Five Star Roast Chicken' known in Thai as 'Kai Yang Ha Daw.'

(b) Changing morphological elements of existing lexical item in English and Thai: the writers construct three types of lexico-morphological variation of the remaining English and Thai words. First, misspellings due to mispronunciation are "Monopolated (Monopolised), ensorcellment (encirclement), and precint (precinct)". Next, prefixes and suffixes are added into the remaining lexicons - un-pawn, karmically, and farangy. Last, a suffix is substituted to an English word - un-performing loans.

Compared to other Englishes, the English trademark words "Coke and Coca Cola" used for any carbonated beverages by some Thais become coinages in Thai English as does the word 'Colgate' that is used for any toothpaste in Singapore English (Low and Brown 71). Moreover, the words "farangy and karmically" are morphologically similar to the Singapore English 'kiasuism' and 'itchified' that have 
been used by Singaporeans (Wong 119). Furthermore, the neologisms "dubbers, un-pawn, and un-performing loans" are equal to the Nigerian English one 'invitee' identified by Bamgbose (106-107) (qtd. in Bamiro, "Nigerian Englishes" 12) since they are invented with new prefixes and suffixes in English. Besides, the words "precint, ensorcement, and Monopolated" are created in the parallel to the Pakistani English word 'soothability' in Zulfikar Ghose's The Murder of Aziz Khan (1967) (Rahman 7), the Philippine English word 'jolibee' or a famous Filipino brand of fast food in an poem DH Sunday, Hong Kong (2001) by Isabela Banzon Mooney (Tope 273-274), and the Hong Kong English word 'Joss' in James Clavell's Nobel House (Vittachi 2000 411) because of misspelling.

\section{Semantic Shift}

English items in which semantic elements are shifted in the Thai context are reflected in words whose new meanings are only slightly expanded from their existing ones. They are 'Nature' (the universe's ruler in Buddhism), 'soul mate' (best friend), 'son' (a member of the village), 'clean' (good or suitable), 'eat' (to make love), 'eating' (corrupting), and 'walking' (manipulating/bribing). One of these words from SDC is found below.

Ex. 9

"Yes, for a fee an agent known in Siamese as 'naamaa' (horse face) has approached me. He'll do all the form filling and walking so that the driving license could be issued without fail" (Sudham 494; bk. 2, ch. 20).

The word 'walking' is an act of reaching the goal. This walking implies speed but is understood as violating social rules as the "walker" gives a reward in the form of a bribe to obtain the license.

The words 'son' in Thai English and 'wife' in Nigerian English in Chinua Achebe's novel Anthills of the Savannah (Bamiro, "Nativization" 320) share a certain feature. In north-eastern Thais' views, 'son' is shifted to a son of all villagers. Likewise, the word 'wife' of an African husband refers to the wife of a community.

\section{Hybridization}

Hybridization involves the process of compounding. It is a lexical item containing "two or more elements having at least one item from Thai and the other from English" (Chutisilp 142). The writers have invented two main systems of ThaiEnglish hybridization - open and closed sets. An open-set item is considered 'open' since there are no grammatical constraints on the selected elements of the lexicon. Meanwhile, a closed-set item involves at least one element belonging to the closed system of South Asian languages such as the suffix 'wallah' (Kachru, Indianization 153-154). From this concept, 'Thai words with English suffixes' are adapted as a criterion for classifying the two systems of hybridization. 
(a) Open Set Items are grouped into four classifications below.

Thai item as modifier refers to a hybrid formation in which a word in Thai or other vernaculars in Thai society modifies an English word (head). This is evident in CLD.

Ex. 10

In Auntie Jin's house, there was no living room, but the Benjarong room (Pinkayan 22; ch. 1).

The word 'Benjarong room' is hybridized as the English head 'room' is modified by the Thai noun 'Benjarong' (Thai porcelain designed in five primary colors). Other examples are takraw ball, plu leaves, Bo tree, plataphien mobile, ramwong music, farang couple, mayom branches, and khaopansa season.

Thai item as head is a Thai word (noun) as a head and modified by English nouns, adjectives, and adverbs, etc. Some instances are Amethyst pohngkham, South Sathorn, plastic khan, plum colored phatoong, and burly, blue-eyed farang.

English and Thai items as modifiers involve English nouns as heads which are modified by compounds of English and Thai words that are either adjectives or adverbs or conjunctives with commas and hyphens such as 'two-saleung top', 'bright green sali pastry', and 'tall, upright and fair farang man.'

Thai and English items as modifiers refer to English heads that are modified by a combination of Thai and English words respectively like 'Rath Pardon Declaration'.

(b) Closed Set Items are Thai lexical items with three types of English suffixes.

Inflectional suffixes: Thai items with inflectional suffixes are divided into four groups: '-s', '-ed', '-ing', and '-er' forms. Examples of each group are 'farangs', 'waied', 'Vipassana-ing', and 'somnolent Esarner.'

Derivational suffixes: Two types of English derivational suffixes "the -ian and -ness forms" are added to Thai words - 'true Isanian' and 'untouchable farangness.'

Derivational and inflectional suffixes: Only two items are found, 'Bangkokians' and 'Napotians.' The suffixes "-ian and-s form" are attached to the noun 'Bangkok' 
while the consonant ' $t$ ' must be added to these suffixes for compounding the word 'Napo'.

Like previous research in Thai English, the items 'yang tree,' 'bo tree', and 'takraw ball' in this study are found in the autobiography 'My Boyhood in Siam. Likewise, the word 'farang' is blended with many English words for two positions, heads and modifiers. For instance, the item 'farang couple' resembles that found in the novel Until the Karma Ends: A Plot to Destroy Burma (Watkhaolarm 150,155). Compared to other Englishes, the word 'farang' is also combined with an English inflectional suffix's'; the item 'big-built farangs' is similar to the Indian English hybrid 'liftwallahs' in Salman Rushdie's writing (Langeland 20). Moreover, the invention of the item 'the sanuk-seeking bankers' goes along with the Malaysian English hybrid item 'the lalang-fringed path' in K.S. Maniam's The return (Cesarano 43). Besides, the item 'two-saleung top' yields the item 'pre-kaak times' of Malaysian English in Che Husna's Pak De Samad's Cinema (Fadillah Merican 118).

\section{Reduplication}

Reduplication represents an extra-meaning to the basic word or parts of words which are repeated. In Standard English, Randolph Quirk et al. (1570-1580) state that "it is used to imitate sounds, 'tick-tock', of a clock and to intensify - tip-top", etc (qtd. in Low and Brown 77). In New Englishes, reduplication of indigenous words is also presented in English texts. In this study, five strategies of word reduplication are used.

(a) To give double force: Here reduplication concerns an emphasis of certain nouns, adjectives and adverbs, as segments in a sentence for more understanding (Mehrotra, "Reduplication" 46). An example from Thai words in SDC is shown.

Ex.11

They are clever and hard-working, whereas we Siamese prefer to take life at our ease, sabai sabai, to be lazy and spendthrift (Sudham 94; bk. 1, ch. 5).

The word 'sabai' is repeated to emphasize pleasure in Thai. Other words are "Sadhu! Sadhu! Sadhu?" (amen) and 'Jek Jek' (Chinese people). An example in English from STS is given.

Ex. 12

“Think black, Wichu. That's what we want. Black, black, black, black, black" (Lapchareonsap 57; "Draft Day”).

This reduplication represents the black ticket indicating 'exemption from draft' that Thai men hope to get instead of the red ticket that means 'to be a soldier. 
Other words are "We gambled, gambled selfishly, gambled [...]" (Lapchareonsap 209) and "He's mute, mute, mute" (Sudham 32).

(b) To make the tone informal: A writer can use reduplication to increase intimacy in speech patterns for humor (Mehrotra, "Reduplication" 48). In this study, the taboo 'ass ass ass' (Lapchareonsap 129) and the Thai interjection 'tra la la la' (Sudham 33) are repeated for ironic teasing.

(c) To imitate sound: Reduplication conveys a writer's perceptions of sounds uttered by human beings, animals, and machines in his or her cultural background, namely in Thai (Chutisilp 192). This is evident in the chicken's sound in UOS 'peck, peck, peck, peck' (Supunpaysaj 105) and sound of a machine in DFS 'rat-tat-tat' (Somtow 116).

(d) To invest a word with new meaning: Words repeated involve "a process of semantic shift" (Mehrotra, "Reduplication" 47). In this study, a kinship term in DFS "a great-great-great-great aunt" (Somtow 20) is repeated with Thai translation for the plural meaning - the older relatives.

(e) To intensify: This form of reduplication is different from other types in which the same words are repeated. It refers to two words in which similar phonological and semantic segments are reduplicated into a single word (Low and Brown 78). Only two Thai items are found: 'Tid-Toy' and 'Nid-Noy' (Sudham 122). These Thai names become sound-connecting words.

The reduplication of Thai words for double force is similar to that of Malay and Cantonese words in Singapore English 'agak agak' (estimate) and 'tsip tsip' (fold) respectively (Low and Brown 77-78). Moreover, a reduplication of adjectives in the word 'a great-great-great-great aunt' parallels "high, high horses" in an Indian English novel Nation of Fools (1985) by Balraj Khanna (Patil 113). Further, the expression "We gambled, gambled selfishly, gambled [...]" seems to be similar to the item "he ate and ate and ate [...]" in a Thai English novel Little Thing (1973) by Prajuab Thirabutana (Chutisilp 144) due to a repetition of verbs.

\section{Acronyms}

Acronyms are abbreviations which are formed by "the use of initial letters of the words" (Bauer 237). Indeed, the selected fiction contains many acronyms in English. However, only the innovative acronyms are illustrated in World Englishes, especially from the novel 'SDC.' Only one stands for Thai abbreviations, 'TC' from “The Honourable Thaninsak Chainarongwan MP” (Sudham 389; bk. 2, ch. 11). English initials are created for the Thai context - 'NPF' (the National Peacekeeping Force) and 'CCD' (the Confederation of the Campaign for Democracy) (701, 705; 
bk. 2, ch. 36). These acronyms were used during the political movement for the actual democracy in Thailand, in May 1992.

The Thai abbreviation in English ' $\mathrm{TC}$ ' is equal to the Japanese acronym in English 'NHK' (Nippon-Hoso Kyokai) or the national public television of Japan (Stanlaw 186187) because of the Englishization process. Moreover, the acronyms 'CCD' and NPF' in Thai English are similar to the Hong Kong English 'PLA' (the People's Liberation Army) (Cummings 28) due to lexical innovations adopted in political contexts.

\section{Clipping}

Clipping is a strategy of shortening a long word for simpler communication. Only the novel 'SDC' provides two kinds of clipped English and Thai words as follows:

(a) Back-clipping refers to words in which back segments are shortened such as 'Sa-u' (Saudi Arabia), 'Chula' (Chulalongkorn University) (Sudham 360, 498; bk. 2 ch. 8, 20), and 'com' (communist) (96; bk 1, ch. 5).

(b) Fore-clipping involves words in which the front segment is reduced. Only one word is found, 'Panom' (144; bk. 1, ch. 7). This word, a province in Northeastern Thailand, has been called because its fore part 'Nakorn' has been used as the fore part of many provinces in Thailand like 'Nakorn Sawan' (a province in central Thailand).

The word 'com' in Thai English yields the Nigerian English word 'video' (video cassette recorder) (Bamiro, "Innovation" 14) because the back parts of the words are clipped. Likewise, the word 'Panom' in Thai English seems to resemble the Zimbabwean English word 'Spekshen' (Inspection) in Shimmer Chinodya's Harvest of Thorns (1989) (Bamiro, "The English" 103) and the word 'cher' (teacher) in Cambodian English (Moore and Bounchan 120) although the former is an indigenous item; moreover, this Thai word can be related to the word 'dik (adik or younger sister/brother) in the Malaysian English novel Green is the Colour (Puthucheary 171) as both represent the fore-clipping of the indigenous items although the former is not marked by an apostrophe.

\section{Ellipsis}

Ellipsis is similar to clipping in that a long word is shortened; the back segment of a word is omitted while the front part is left. However, it is distinct because it can be used for either a compound word or a long string of phrases. Indeed, ellipsis is a cohesive strategy that reduces output by deleting material that the speaker assumes the hearer can understand from the linguistic or interaction context (Bamiro, "Innovation" 14). In this study, only the book 'DFS' provides two instances of ellipsis: 'namo dasa' (namo dasa bhakavato arahato samma sambuddhatsa) (Somtow 76;

“The Steel American") and 'City of Angels Etc.' (10-11; "Dragon's Fin Soup”). The 
former is the Pali-Sanskrit mantra in Buddhists' prayers while the latter that is translated from 'Krungthep Etc.' or Krungthep Mahanakorn Amornratanakosin [...] is a contraction of Bangkok Metropolitan. Therefore, ellipsis in Thai English is found in words in Pali-Sanskrit and English languages.

It appears that the word 'namo dasa' holds a partial similarity with the word 'galvanize' (galvanized iron roof) in the Trinbagonian English novel A House for $M r$. Biswas (1961) by V.S. Naipaul (Bamiro, “The English" 185-186). Although this Thai English word is derived from a very long non-English item, its back constituent is deleted.

It is noteworthy that 'reduplication, acronyms, and ellipsis' are considered the new categories of lexical creativity that appear in only the present study; they were not found in previous studies in lexicon of Thai English and Asian Englishes.

\section{Thai English as a Variety}

Ten categories of lexical creativity in Thai English fiction share many features of not only other Asian Englishes but also African, and Caribbean varieties of English. This assertion is valid since the selected Thai English writers and other writers of Englishes are similar in that they use English as a first language and employ such lexical innovations as salient linguistic devices to develop the characters, plots, settings, as well as narratives and dialogues as a means of expressing their national identity in English. This seems to indicate that English in Thailand is developing its own linguistic norms in parallel with the Outer and Expanding Circle Englishes. However, this evidence is insufficient to determine the ten features as indicators for a Thai English lexicon. A discussion of these features in relation to the conceptual framework is given below to determine the extent to which these features are from a Thai variety of English.

\section{Indicative Features of Thai English Words}

Indeed, all those categories in this study parallel the five concepts that are indicative of non-native English words.

(1) Contextualization: three categories yield this concept. Firstly, lexical borrowing or lexical transfer appears in sub-categories 'independent and reduplicating loans'. This also covers 'greeting words' which is mentioned in 'speech functions' (Kachru, Indianization 112). Secondly, loan translation covers the terms 'translation', 'calques,' 'collocations', and 'cursing.' Translation refers to word-for-word translation while calques concern 'rank-bound translation'. Likewise, collocations are named as 'fixed collocations'. Besides, 'cursing' under 'speech functions' is also categorized here. Lastly, modes of address and reference become an individual group in this study while Kachru 
includes them in the speech functions (112). These categories seem to be indicative of a contextualized Thai English lexicon.

(2) Innovation: Hybridization plays a highly significant role as an indicator of lexical innovation (Kachru, Indianization 153). This study contains a large number of Thai English hybrid items in relation to open and closed sets in the framework. In the same token, the findings of hybridization and other groups like modes of address and reference as well as collocations serve Kachru's linguistic innovation ("Standards" 18, 21).

(3) Nativization: The emerging categories parallel those suggested in Kachru's nativization of cohesion and cohesiveness - collocations, hybridization, and loan translation ("Alchemy"). Likewise, four groups of the findings can be seen according to Schneider's structural nativization - lexical borrowing from indigenous languages for toponymes, fauna and flora, coinages, semantic shifts, and hybridization.

(4) Transcultural creativity: The structure of loan translation and ellipsis in this study conforms to the notion of 'transcultural creativity' in World Englishes literature (Kachru "Transcultural”). 'Word-for-word translation' suits the first type of intercultural crossover named 'intelligibility' as only Thai words with denotative meanings are translated in English, with the assumption that there is no problem with other non-Thai readers. Meanwhile, 'fixed collocation' fits the second type named 'comprehensibility' because particular religious and ritual canons of Thai words are translated - 'spirit doctor', 're-born', and 'temple-arrested'- requiring connotative meaning for comprehension. Likewise, the elliptical item 'namo dasa' parallels the latter type due to semantic restrictions in Buddhist mantras.

(5) Localization: Only varietal range and non-standard English forms of Strevens's localized forms of English are evident in this study. In varietal range, 'registers' of lexical creativity in particular categories are firstly revealed. From loan translation, the words 'Heart-Stopped Building' (mortuary building) and 'taste-bud cheating stuff' (MSG) present registers of medicine and food science, respectively. In the context of lexical borrowing, the word 'chok muay' (Thai boxing) is derived nfrom the sports register. From hybridization, the item 'Poodhydepark' (Hyde Park speech) is used in the political register. Additionally, a clipped word 'com' is of a political register, "Panom, and Sau" are based on the geographical register - a province and a country respectively, as well as 'Chula' is referred to as an education register. All the different registers serve the literary register of language in Thai English fiction. Secondly, formality-familiarity is always found in modes of address and reference. The most formal words belong to the royal Thai family members and Buddhist priests. The next respectful items are applied to commoners with different occupations and classes. The neutral degree is seen in kinship terms. The final group 'intimacy' appears in friendly terms for human beings like 'phuan' 
and for pets ' $A i$ ' and ' $E$.' In addition, a swear word under 'loan translation' (animal) and taboos from lexical borrowing (Huakuay and Dawson) show appropriateness of Thai cursing and colloquial items in English. With regard to non-standard forms, particular categories present a trivial variation in lexis

- reduplicating lexical borrowing, word-for word translation, reduplication of English items, and acronyms. These are assumed as less problematic items to non-Thai readers.

\section{Conclusion}

A comparison between the ten categories of lexical creativity in Thai English and those of other Englishes as well as a discussion of the five indicators of Thai English lexicon interpreted by the framework are crucial for an examination of whether Thai English constitutes a variety. Those categories represent evidence of this new variety as they are supported by the five indicative features. Hence, the term 'Thai English lexicon' seems to be accepted; however, the concept of a Thai variety of English judged with only the lexical features is only partially recognized. According to Kachru (Asian Englishes 14), English in Thailand belongs to the Expanding Circle. Considering Strevens's world map of English (86), English in this country is not a strand of any British or American English as a history of a colonial language is absent. Moreover, its localized forms mirror a foreign language (an international type) rather than a second language (an intranational type). Similarly, English in Thailand did not encounter the dynamic linguistic process during the British or American colonization as illustrated in Schneider's model. Significantly, English in Thailand was introduced by the British diplomats and merchants in the 17th century and the American missionaries in the 19th century, but the notion of Thai English has neither been substantially addressed by Thai scholars of English studies nor realized by Thai users of English. On the other hand, the importance of British/ American English as the best model of linguistic, literary, cultural, functional and pedagogical norms is deeply embedded in the Thai people's perspectives on English.

Analysis carried out in this study does not indicate that the term 'Thai English' is an established variety. A more suitable term for it should be 'a developing variety' because English in Thailand needs many more empirical studies on phonological, grammatical, discourse, pedagogical, and professional levels from various texts and methodologies before it can be recognized as an institutionalized variety. 


\section{Works Cited}

Albakry, Mohammed and Patsy Hunter Hancock. "Code-Switching in Ahdaf Soueif's the Map of Love." Language and Literature 17.3 (2008): 221-234.

Azirah Hashim. "The Use of Malaysian English in Creative Writing." Asian Englishes 10.2 (2007): 30-43.

Bamgbose, Ayo. "Torn between the Norms: Innovations in World Englishes." World Englishes 17.1 (1998): 1-14.

Bamiro, Edmund. "Nigerian Englishes in Nigerian English Literatures." World Englishes 10.1 (1991): 7-17.

—. "Innovation in Nigerian English." English Today 10.3 (1994): 13-16.

- . "The English Language and the Construction of Cultural and Social Identity in Zimbabwean and Trinbagonian Literatures." PhD Thesis. U of Saskatchewan, Saskatoon, 1997. ProQuest Dissertations and Theses. Web. 1o Dec. 2011.

-. "Nativization strategies: Nigerianisms at the Intersection of Ideology and Gender in Achebe's Fiction". World Englishes 25.3/4 (2006): 315-328.

-. "Transcultural Creativity in World Englishes: Speech Events in Nigerian English Literature." International Journal of Linguistics 3.1 (2011): 1-16.

Bauer, Laurie. English Word-Formation. Cambridge: Cambridge University Press, 1983. Bolton, Kingsley. Chinese Englishes: A Sociolinguistic History. Cambridge: Cambridge University Press, 2003.

-. "English: The Asian Way." Bangkok Post. 2-8 Sep. 2003 <http.//www.bangkokpost. com/education/site2003/cvseo203.htm>

Butler, Susan. "World English in an Asian Context: The Macquarie Dictionary Project." World Englishes 15.3 (1996): 347-357.

—. "A View on Standards in South-East Asia." World Englishes 18.2 (1999): 187-198.

-. "The Needs of Dictionary Users in South-East Asia." English is an Asian Language: The Thai Context. Ed. Mark New brook. New South Wales: The Macquarie Library, 1999. 80-94.

Cesarano, Gianna. "Ethnolectal and Sociolectal Creativity in Malaysian Literature with the Reference to the Work of K.S. Maniam." Diss. U of Malaya, Kuala Lumpur, 2000.

Chutisilp, Pornpimol. "A Sociolinguistic Study of an Additional Language English in Thailand." Diss. U of Illinois, Urbana-Champaign, 1984. ProQuest Dissertations and Theses. Web. 20 Nov. 2011.

Cummings, Patrick J. "A Study of Lexical Innovation in Hong Kong English." U of Hong Kong, 2007. The HKU Scholars Hub. Web. 25 Nov. 2011.

Dasgupta, Probal. The Otherness of English: India's Auntie Tongue Syndrome. New Delhi: Sage Publications, 1993.

Dissanayake, Wimal and Mimi Nichter. "Native Sensibility and Literary Discourse."Discourse across Cultures: Strategies in World Englishes. Ed. Larry E. Smith. New York: Prentice Hall, 1987. 114-122.

Fadillah Merican. "Going Native and Staying Strong: Malaysian Fiction in English." English is an Asian Language: The Malaysian Context. Eds. Halimah Mohd Said and N. Keat Siew. New South Wales: The Macquarie Library, 2000. 107-124. 
Fernando, Siromi. "Style Range in Sri Lankan English Fiction: An Analysis of Four Texts." World Englishes 8.2 (1989): 119-131.

Govendan, Umavathy. "The Use of Malaysian English in Creative Writing by Malaysian Writers." Diss. U of Malaya, Kuala Lumpur, 2001.

Hill, Jimmie. "Revising Priorities: From Grammatical Failure to Collocational Success." Teaching Collocation: Further Developments in the Lexical Approach. Ed. Michael Lewis. London : Heinle/Cengage Learning, 2000. 47-69.

Jantori, Parinda. "Lexical Innovation and its Usage in Thai English." MA Research report, Chulalongkorn University, Bangkok, 2007.

Jenkins, Jennifer. World Englishes: A Resource Book for Students. London: Routledge, 2003.

Johnson, Robert Keith. "International English: Towards a Viable Target Grammar of English for International Communication." Proceedings of the First Hong Kong Conference on Language and Society, University of Hong Kong, Hong Kong, 25-28 July 1988. Hong Kong, 1988. 1-18. Print.

Jones, Rodney H. "Creativity and Discourse." World Englishes 29.4 (2010): 467-480. Joseph, Clara A. "Language in Contact and Literatures in Conflict: Text, Context, and Pedagogy.” World Englishes, 24.2 (2005): 131-143.

Kachru, Braj B. Indianization of English: The English Language in India. Oxford: Oxford University Press, 1983.

-. "Standards, Codification and Sociolinguistic Realism: The English Language in the Outer Circle." English in the Word: Teaching and Learning of Language and Literature. Eds. Randolph Quirk and Henry G. Widdowson. Cambridge: Cambridge University Press, 1985. 11-36.

-. The Alchemy of English: The Spread, Functions and Models of Non-Native Englishes. Oxford: Pergamon Press, 1986.

- . "Transcultural Creativity in World Englishes and Literary Canons." Principles \& Practice in Applied Linguistics: Studies in Honour of H.G. Widdowson. Eds. Guy Cook and Barbara Seidlhofer. Oxford: Oxford University Press, 1995. 271-287.

-. Asian Englishes: Beyond the Canon. Hong Kong: Hong Kong University Press, 2005.

Kachru, Yamuna and Larry E. Smith. Cultures, Contexts, and World Englishes. New York: Routhledge, 2008.

Kirkpatrick, Andy. "Theoretical Issues." English in Southeast Asia: Features, Policy, and Language in Use. Eds. Ee Ling Low and Azirah Hashim. Amsterdam: John Benjamins, 2012.

Langeland, Agnes S. “Rushdie's Language." English Today 12.1 (1996): 16-22.

Lapchareonsap, Rattawut. Sightseeing. Sydney: Pan McMillan Australia, 2005.

Low, Ee Ling and Adam Brown. English in Singapore: An Introduction. Singapore: McGraw-Hill, 2005.

Lowenberg, Peter H. "The Making of Ethnicity in Malaysian English: Nativization and Its Functions." World Englishes 11.2/3 (1992): 251-258.

Lowry, Ann. "Style Range in New English Literatures." The Other Tongue: English across Cultures. 2nd ed. Ed. Braj B. Kachru. Urbana: University of Illinois Press, 1992. 283-298. 
Mathias, Philip. "Lexical Innovation and the Use of English in Thai Contexts on Internet Forums.' BU Academic Review 10.1 (2011): 8-13.

Mehrotra, Raja R. "Indian Literature in English." English across Cultures \& Cultures across English: A Reader in Cross-Cultural Communication. Eds. Ofelia Garcia and Ricardo Otheguy. Berlin: Mouton de Gruyter, 1989. 421-439.

—. "Reduplication in Indian Pidgin English." English Today 13.2 (1997): 45-49.

Meyler, Michael. "Sri Lankan English: A Distinct South Asian Variety." English Today 25.4 (2009): 55-60.

Moore, Stephen H. and Suksiri Bounchan. "English in Cambodia: Changes and Challenges." World Englishes 29.1 (2010): 114-126.

Pandharipande, Rajeswary. "On Nativization of English." World Englishes 6.2 (1987): 149-158.

Patil, Z.N. Style in Indian English Fiction. New Delhi: Prestige, 1994.

Pinkayan, Salisa. Chalida. Bangkok: Asia Book, 2002.

Platt, John T., Heidi Weber, and Ho Mian Lian. The New Englishes. London: Routledge \& Kegan Paul, 1984.

Rahman, Tariq. "Linguistic Deviation as a Stylistic Device in Pakistani English Fiction." Journal of Commonwealth Literature 25.1 (1990): 1-11.

Rita Abdul Rahman Ramakrina. "Lexical Borrowing in Malaysian Short Stories." The Ninth Humanities Postgraduate Conference, Curtin University of Technology, Perth, 5-8 November, 2008. <http://hgsoconference.curtin.edu.au/previous/rama.cfm>

Schneider, Edgar W. Postcolonial English. Cambridge: Cambridge University Press, 2007.

Somtaw, Sucharitkul P. Dragon's Fin Soup: Eight Modern Siamese Fables. 2nd ed. Bangkok: Asia Books, 2002.

Stanlaw, James. "English in Japanese Communicative Strategies." The Other Tongue: English across Cultures. 2nd ed. Ed. Braj B. Kachru, Urbana: U of Illinois Press,1992. 178-208.

Strevens, Peter. Teaching English as an International Language: From Practice to Principle. Oxford: Pergamon Institute of English, 1980.

Sudham, Pira C. Shadowed Country. Bangkok: Asiashire, 2004.

Supunpaysaj, Supasiri. The Umbrella and Other Stories. Bangkok: First Printing, 1998.

Tan, Siew Imm. "Lexical Borrowing from Chinese Languages in Malaysian English."

World Englishes 28.4 (2009): 451-484.

Velautham, Lalitha. "A Discourse Analysis of Three Malaysian Short Stories." Diss. U of Malaya, Kuala Lumpur, 2000.

Vittachi, Nury. "From Yinglish to Sado-Mastication." World Englishes 19.3 (2000): 405-414.

Watkhaolarm, Pimyupa. "Think in Thai, Write in English: Thainess in Thai English Literatures." World Englishes 24.2 (2005): 145-158.

Wong, Lian-Aik. "A Descriptive Analysis of the Varieties of Singapore English as Recreated by Singapore Writers of Fiction." Diss. Indiana U of Pennsylvania, 1992. ProQuest Dissertations and Theses. Web. 15 Oct.2011.

Yang, Jian. "Lexical Innovations in China English." World Englishes 24. 4(2005): 425-436. 
Yap, Arthur. "The Use of Vernacular in Fiction Written in English in Singapore and Malaysia." RELC 7.1 (1976): 64-71.

Zhang, Hang. "Bilingual Creativity in Chinese English: Ha Jin's In the Pond." World Englishes 21.2 (2002): 305-315. 